\title{
15
}

\section{Students' Perceptions of the Technological Supports for Problem-based Learning}

\author{
Willie Yip \\ The Hong Kong Polytechnic University, Department of Computing, Hung Ham, Hong Kong, \\ China \\ cswiyip@comp.polyu.edu.hk
}

Keywords: problem-based learning, support tools, students' perceptions, technological supports

\begin{abstract}
This paper reports students' perceptions of the technological supports that assist problem-based learning (PBL). There are a number of tasks in the PBL processes, which can be supported by technological advances. A Web-based system has been developed to support the problem-based learning strategy. The system provides facilities to both teacher and students to facilitate learning and teaching. These include on-line teaching materials retrieval, a discussion area for problem analysis and brainstorming, a facility for project planning and monitoring, a private group area for the purposes of discussion, a facility for the submission of development work and learning resources, and a posting area to display good work to motivate students. The progress of the students can be monitored and feedback can be given to them. This paper presents a pilot study of student views of and preferences for various technological supports used to enhance learning effectiveness.
\end{abstract}

\section{INTRODUCTION}

The author undertook a learning and teaching project in the autumn of 1999 , with the aim of promoting problem-based learning in the subject Information Systems Analysis. The PBL approach was introduced for the first time to teach Information Systems Analysis to second year students in the Higher Diploma in Information Systems programme. It was the only 
subject in the programme that used the PBL approach, with which students had no prior experience. However, it was envisaged that students would learn better with the PBL approach, which is facilitated by technological advances.

Problem-based learning is a promising recent development in tertiary education, which recognises the need to develop problem-solving skills as well as the necessity of helping students to acquire necessary knowledge and skills (Boud and Feletti 1997). The amount of direct instruction is reduced in problem-based learning, as students assume greater responsibility for their own learning. Students are given ill-structured problems through which they develop high-order thinking and problem-solving skills. The shift in the teaching and learning process is more student-centred than teacher-centred. The teacher as knowledge provider becomes less important as students learn from other students, the World Wide Web (WWW), and from other information resources. The role of the teacher is to encourage student participation, provide guidance to students, offer timely feedback, and also assume the role of learner (Roblyer et al. 1997). A problem case, unlike a case study, provides less information to students and requires them to do more information searching. There can be alternative solutions to a problem, through which students learn to make evaluations and justifications. Problem cases, which require students to tackle ill-structured problems, not only develop interpersonal communication and social skills, but also stimulate critical thinking, creativity, and problem-solving skills.

Many universities around the world are using the WWW in direct support of teaching and learning, as both a primary means of information delivery and a supplement to classroom teaching (Harasim 1999). The use of the Web as a teaching resource can benefit students (Milheim and Harley 1998, Sloan 1997). Students can learn better when the pedagogical process of PBL is supported by technology to foster teaching and learning. Learning and teaching courseware is available (Blumenstyke 1999, Frederickson 1999) and the author's university has been using WebCT as the teaching platform since September 1999. Nevertheless, WebCT features are unable to support the various PBL processes, in particular project planning and controlling, and private discussion facilities for collaborative learning, which are important processes within PBL. Thus, a Web-based system has been developed to support PBL instead. The technology provides facilities for both teacher and students to facilitate learning and teaching. This paper presents a pilot study of student perceptions of the technological supports used to enhance learning effectiveness. 


\section{HYBRID PBL APPROACH TO EFFECTIVE LEARNING}

The introduction of a hybrid approach to PBL may be more appropriate for undergraduates. A full PBL approach with less lecturing, more students working in small groups, and more self-direct learning, may not be appropriate initially for two reasons. First, most undergraduate students are accustomed to teacher-centred learning and they may need a short period to get used to the PBL setting. Another consideration is that their academic achievements may not be the best. Expecting students to be able to read well and provide answers to ill-structured problems initially may not be workable. Second, every subject is time-tabled and designated with both lecture and tutorial hours. As such, this is an institutional constraint, because teaching activities need to follow these patterns. However, there follows a gradual reduction in formal lectures for knowledge dissemination, with the replacement of more discussion activities that take place during lecture hours.

A number of PBL strategies have been tried in learning and teaching (Tang et al. 1997). The author used the hybrid problem-based learning strategy, with students working in teams of six, as follows.

- Teaching materials can be accessed on the Web and students prepare for classes

- Students are given problem cases that simulate real-life situations

- Brainstorming sessions are held to identify learning issues

- A group project plan is formulated

- Students undertake self-directed and collaborative learning

- Each group of students presents their findings (report writing and presentation)

- Exemplary work is posted on the Web for experience sharing

- Students reflect on what they have learnt through feedback.

The Web-based system provides functionalities to support the various PBL processes are shown below.

\begin{tabular}{|ll|}
\hline PBL processes & Technological supports in the Web-based system \\
Problem cases & Posted on problem case area \\
Identifying learning issues & Problem analysis \\
Group project planning & Group project plan \\
Self-directed learning & Reading - Teaching materials are posted on the \\
& Web (Teaching materials area) \\
& Searching - Information search through the WWW \\
& Understanding - Individual work submission \\
\hline
\end{tabular}




\begin{tabular}{|ll|}
\hline Collaborative learning & Group discussion \\
Report writing and presentation & Teamwork submission \\
Reflection & Feedback, posting area (showing good student \\
& work), bulletin board \\
\hline
\end{tabular}

\section{STUDENTS' PREFERRED TECHNOLOGICAL SUPPORTS FOR PBL}

Table l. Students' preferred facilities on the $\mathrm{W}$ eb site

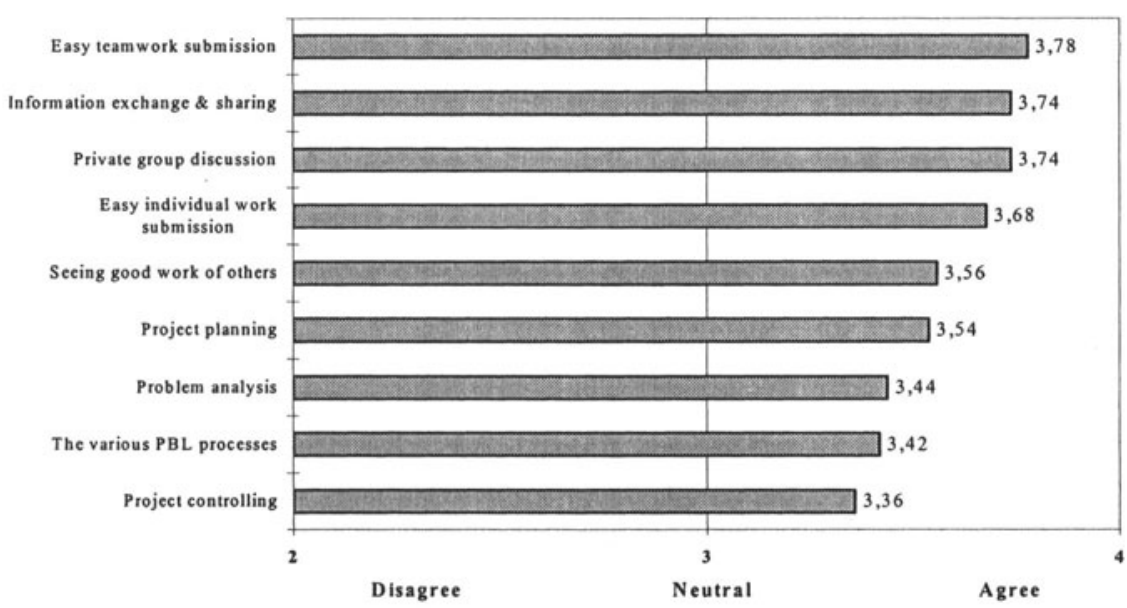

Student learning can be enhanced when the pedagogical process of PBL is supported by technology. A Web-based system provides functionalities to support the various PBL processes. Teaching materials, problem cases and PBL guidelines are posted on the Web. Facilities such as private group area for discussion and brainstorming, a problem analysis area for identifying learning issues, a simple table for group project planning, individual work and teamwork submission facility for on-line work submission, and a posting area for displaying the exemplary student work - are all intended to enhance better learning and teaching. Students were requested to rate their preferred facilities on a scale of 1 to 5 , with 5 being the highest score and 1 the lowest. Table 1 presents students preferred facilities on the Web site. The following sections describe in detail the students' perceptions of the technological supports. 


\subsection{The author's views on posting teaching materials on the Web}

Students are interested in receiving the teaching materials available on a course Web site (Holmes 1999, Weible 1999). They can download subject information (subject syllabus, teaching plan) and teaching materials (lecture notes, review questions, references, problem cases and problem-based learning guidelines). Students are encouraged to develop the habit of making preparations for lectures. They are also encouraged to raise questions for discussion in class and there is little doubt that they will understand the subject better. As students participate more in class discussion, the atmosphere of a lecture session is enhanced. The usual one-way method of communication that most teachers use is dull and uninteresting. Since the teaching materials are stored in PDF format with four pages of materials printed on a page, the content is legible but paper is saved in printing. Teaching materials are useful to students and can be updated easily. The Web-based system also solves the problem of photocopying overhead projector transparencies in the production of handouts.

\subsection{Students' perceptions of receiving teaching resources on the Web}

Despite the tremendous efforts that have been used in preparing the teaching materials and posting them on the Web at the beginning of the semester, it is surprising to find that students do not, in general, use this facility to its best potential. Table 2 presents the students' views of receiving teaching resources on the Web. With the teaching materials available on the Web, students do not make use of the resources in making preparation for lectures. They download the lecture notes for lectures without much preparation. As such, they fail to learn how to prepare for lectures. The number of questions raised in class is the same as with the traditional teaching approach. However, some students do make preparation for lectures and posting teaching resources on the Web can improve their learning style, as they need to print the lecture handouts for lectures. They also find the supplied references useful for obtaining more information. 
Table 2. Students' perceptions of receiving teaching resources on the Web

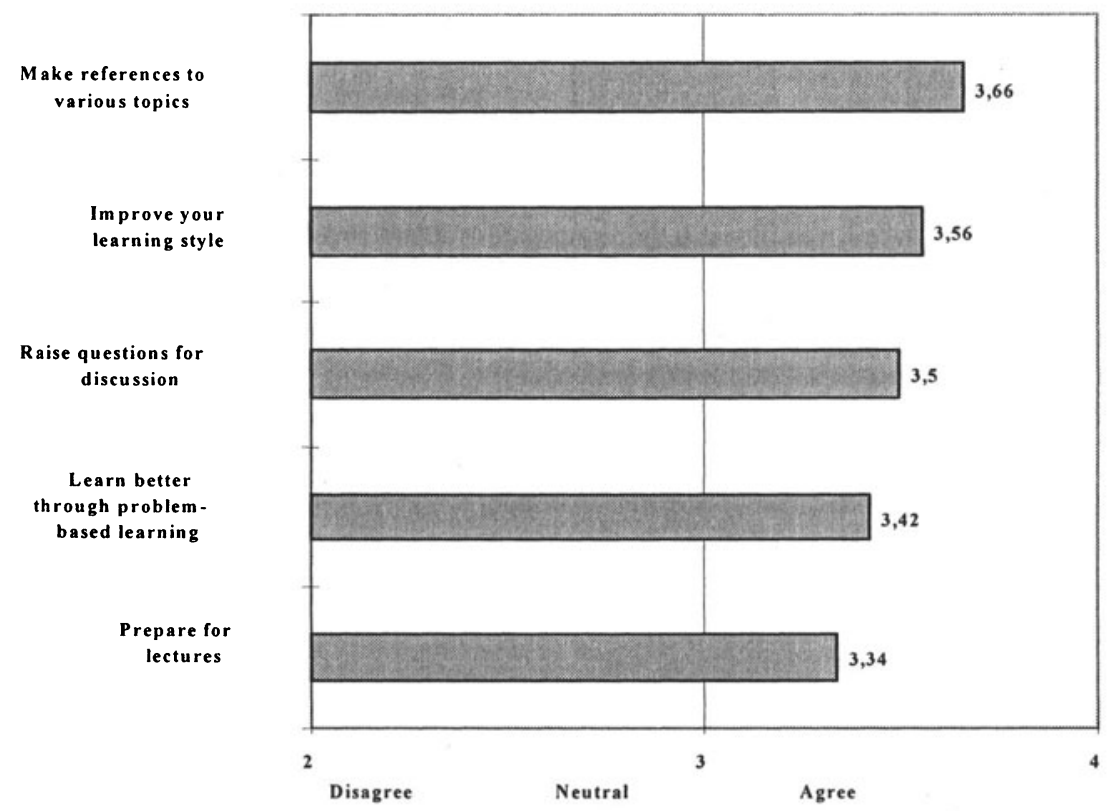

\subsection{Self-directed learning and easy individual work submission}

When students undertake self-directed learning, they use the WWW, which is an excellent tool for searching, containing a number of search engines. To ensure that students read and understand the information that they locate from a number of sites, they are required to write a short paragraph or two summarising their impressions of the information presented at the site. This enables the students to understand the topic, to practice their writing skills, and also to reflect on the work done. The student work can be shared among the team members. When the work is to be submitted electronically, it need not be during office hours, and this provides more flexibility to students. Students in the process of searching for information often encounter two problems. First, some initially do not know how to search for information on the Web. Second, they encounter an information overload problem. However, students have been reminded to select the relevant information rather than all the information. They should also learn how to make group decisions based on the information available. More importantly, they should have skills and knowledge in the use of the 
various WWW search engines and in employing efficient search strategies in information-seeking.

Each student is encouraged to prepare some individual work before they meet as a group. He/she should develop the habit of self-learning and accumulate experience and skills in problem-solving through teamwork situations. A student can contribute towards teamwork in two ways: first, the student takes an active approach to participating in discussion, offers creative ideas, and either proposes a good plan or revises others to arrive at an even better plan. With the Web-based system, the discussion records of each student can be seen and the performance of each individual can be identified. Second, the individual student undertakes the assigned tasks and produces quality work on time. The individual work submission function facilitates the sharing and exchanging of information. There are two ways for students to submit their work. The first way allows a student to present his/her work on their Web site and submit the URL of the page. The other is using the online editor provided by the Web-based system.

\subsection{Public and private Web areas for information exchange and sharing}

Students need a mechanism to share their individual work and the results of their teamwork. The Web-based system is an automatic development environment through which students' work can be accessed, commented on and refined by team members electronically. It enables students to create knowledge and to share among themselves. Two areas, both public and private, are for the posting and sharing of information: a public area for the whole class and a private area for each team. The public area serves as a bulletin board, which is for information dissemination and also for posting the best work in the class. Another important use of this public area is for questions and answers that can clarify misunderstandings of materials. One of the important teaching and learning issues is to motivate students to learn better and to work harder. It has been found that the quality of student work has been declining in recent years and teaching efforts can be maximised to produce better results if students are motivated to learn. The purpose of having an electronic display facility is to create a co-operative learning environment where students benefit from the activities of their peers. At the same time, the posting of good work by students will provide higher motivation for them to perform well. The private area contains communication, the work plan, the individual work and the teamwork. The teacher is permitted to access this area for monitoring work and also to 
provide feedback and guidelines. Other students can benefit by reading the teacher's comments before viewing the information.

\subsection{Collaborative learning and videotaped presentations for feedback}

Students need to practise teamwork and understand that they learn more from people than working as individuals. Group work and team-building skills are essential in organisations (EI-Shinnawyn 1998). Collaborative learning enables students to share and exchange information to arrive at group decision-making and develop a more comprehensive understanding of the subject. A good team generally produces better results, and poor team morale and conflicts between students often lead to poor team performance. In mixed ability groups, the stronger students tend to encourage and motivate the weaker students to achieve better performance levels. At the same time, the stronger students can practise leadership skills and can serve as consultants for their team-mates (Buffington 1998). However, each student should have the opportunity to develop leadership skills. Students should be adaptable to a new team situation, with people having different personalities and experiences. The performance of each team was videotaped at the beginning and at the end of the semester for review feedback. Table 3 presents their views on videotaping their presentation. They valued the opportunity for self-evaluation and assessed how they could improve themselves in presentations.

Table 3. Video-taped presentations for feedback

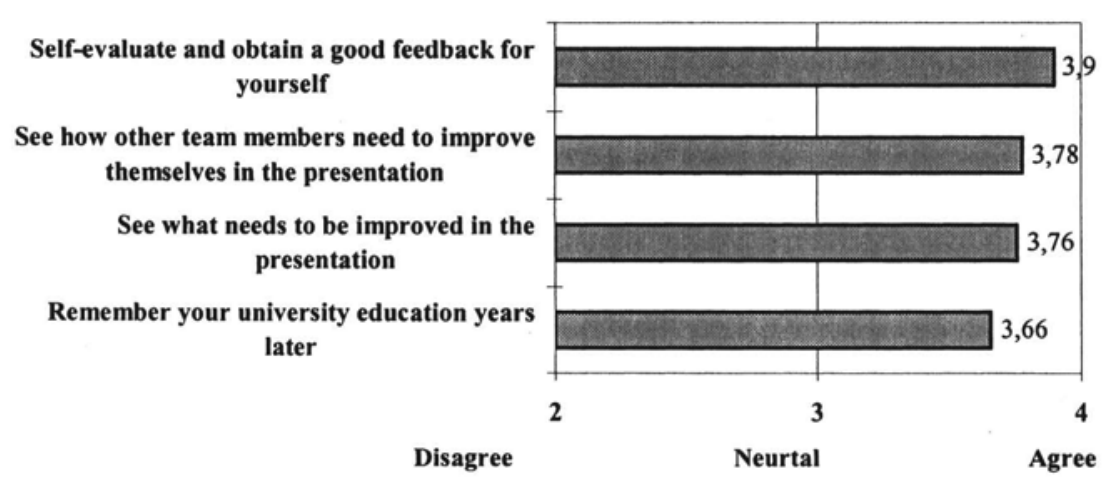


The progress of the tutorial sessions can be more effective and productive since both students and teacher can review the work done by each individual in each team via the Web before the tutorials. Students have increased time for reflection on the problem. Shorter meetings and higher learning productivity are to be achieved. However, teamwork was enhanced with the Web technology, which provided an extra communication facility, and students make use of the Web for sharing and exchanging information.

\subsection{Peer evaluation as part of assessment}

When students are working in a team situation, each student is expected to contribute to teamwork. Students are responsible for completing a project but have no authority to 'tell' other team members to be co-operative. Team learning can only be fruitful when each team member is committed and contributes to the teamwork. The assessment of this subject is continuous, without examinations. There are three components in the formal assessment of each student. They include individual contribution, group work as a whole and peer evaluation by students themselves. Students are assessed by a peer review system, with the intention that every student should contribute positively in a teamwork situation. Peer-grading is performed after each problem case has been completed, and the individual performance such as presentation, tutorial contribution, individual work and team contribution can be measured. Table 4 presents students' view on having peer evaluation of team members. They feel that they can express their satisfaction or dissatisfaction openly. Individual assessment is based on the work produced individually and also on the individual contribution to team work discussions. Individual and group marks are given equal weight. On the other hand, good students should not be penalised if they have been assigned to work with other less hard-working students. Students should be allowed to assess other team members' efforts as this encourages each team member to contribute to the teamwork situation and the team leaders and/or good students deserve higher weighting. Each student is requested to assess his/her members for their relative percentage of contribution to the problem case, and also on the quality of work submitted. The peer evaluation of students relies on the judgment and honesty of the students in making such evaluations. In general, students have been fair in their peer evaluation assessments. 
Table 4 . Having peer evaluation of the team members

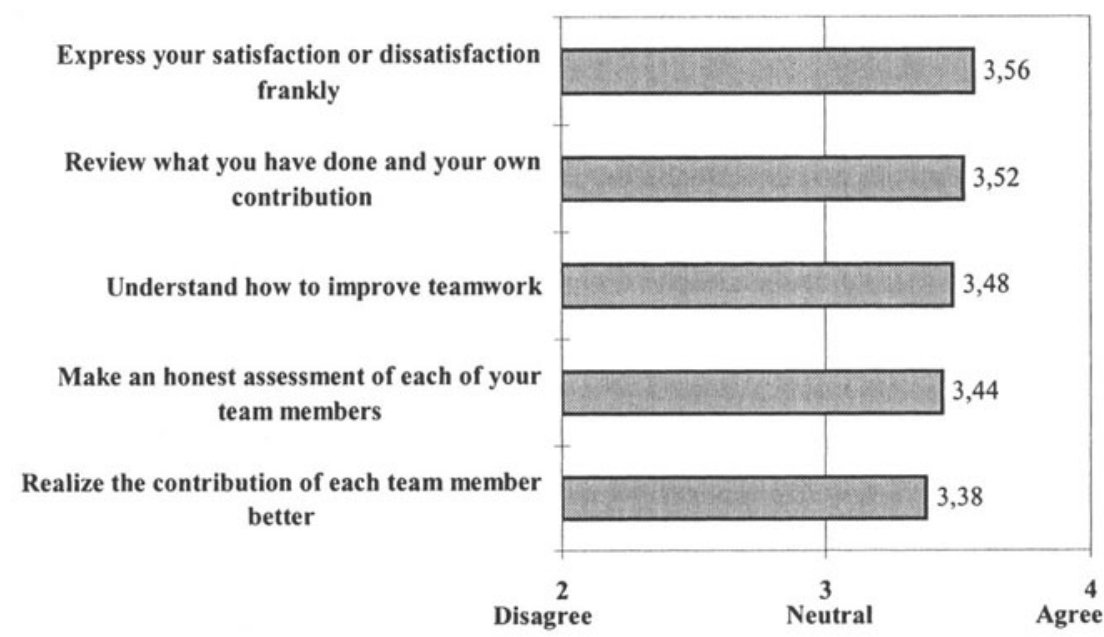

\subsection{Posting board to motivate students}

The purpose of having a posting facility is to create a co-operative learning environment where students benefit from the activities of their peers. At the same time, the posting of good work (reports and presentation files) by students will provide higher motivation for them to perform well. The motivation factor may not be a monetary reward, but recognition by their peers is important. This also facilitates the experience of sharing 'excellent' work in the specified subject, and enables students to learn from good quality work. Other students can benefit by seeing how other teams tackle the same problem, and this can further enrich the knowledge of the students. One of the important learning and teaching issues is to motivate students to learn better and to work harder. Table 5 presents the students' views of having a posting board to exemplify good work. It is evident that the posting facility motivates them to perform better.

\section{FEEDBACK FROM STUDENTS AND DIFFICULTIES ENCOUNTERED}

Students had the experience of using three different types of courseware, and they rated this Web-based system as the best, as it is well designed and 
Table 5. Viewing good work of other teams

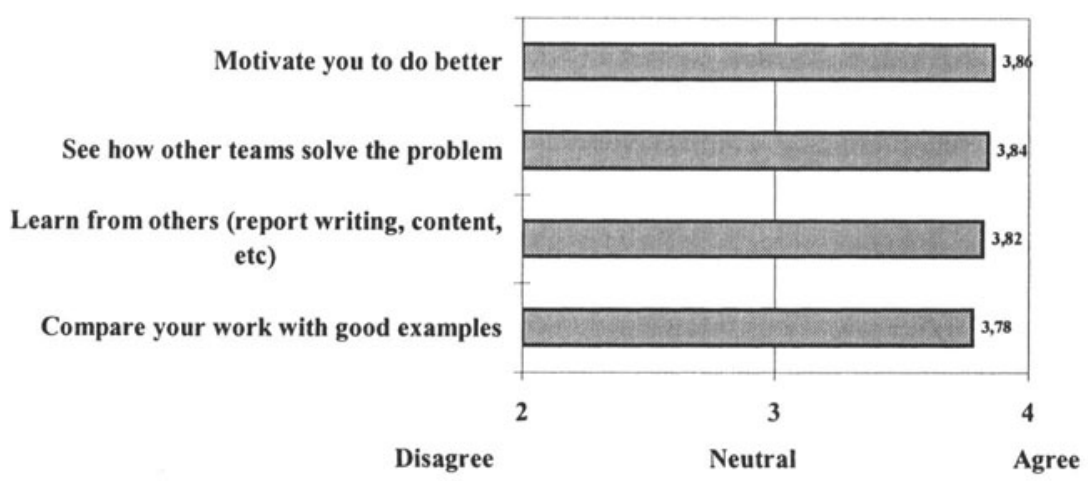

easy to use. The facilities they like include: easy on-line work submission, private area for group discussion, the facility for information exchange and sharing, and the posting board for seeing the good work of other teams. Students tended to spend more time than necessary on searching for information, despite having been guided to look for relevant information rather than all the information. Some students reported that they could search for information on the Web more systematically than before. The learning outcome has been found to be positive, in that students spent more time on the subject.

The workload for the author has increased when compared with traditional teaching without technological support. The progress of the students must be monitored, as there is a need to ensure that each student participates and contributes in teamwork situations. There were also problems of computer virus attacks when students submitted group reports which were found to contain viruses.

\subsection{Problems encountered with using technology}

When asked about problems encountered with using technology to enhance learning, students commented that the discussion board (thread discussion) is not quite as useful as ICQ, e-mail and face-to-face communication. Students tend to like formal meetings better. If their home computer has a problem, they cannot do anything and therefore learning is technology- dependent. Information searching requires a lot of time. They have difficulty in summarising information that is found on the Web, and the Web site does not allow them to submit diagrams. Sometimes, they had 
difficulty connecting to the university's Internet connection. This may affect their discussions with their teammates and also submission of their work. They prefer that the website be designed so that they can make reference to the problem case that they tackled previously.

\section{CONCLUSION}

This paper has described an approach to enhance the teaching of Information Systems Analysis to undergraduate students through PBL with the aid of technological advances. Students have been found to do more reading and engage themselves in problem-solving with problem cases. They realise that teamwork is more important than individual work in problemsolving. The author takes the view that a practical and cost-effective technological solution should be adopted to facilitate PBL. The application of the Web-based system to the various stages of the proposed problembased learning/teaching strategy benefits students. The system allows students to download teaching materials. A private Web area is designed for each team of students to enhance collaborative learning. It can be used for the purposes of communication, project planning, development work, and learning resources for a project team. The public Web site can serve as a bulletin board for information dissemination. A posting area allows the display of students' good work to motivate them to work better. Students have remarked favorably on what they learnt, including: better problem analysis, understanding of how to formulate a project plan and subsequent control of their work, better written and oral communication, teamwork, practicing leadership skills, and better information search via the Internet.

\section{ACKNOWLEDGMENT}

I would like to express my gratitude to the Learning and Teaching Development Committee of The Hong Kong Polytechnic University for providing funding for this project.

\section{REFERENCES}

Blumenstyk, G. (1999) The Marketing Intensifies in Distance Learning. The Chronicle of Higher Education, pp. 27-30.

Boud, D. and Feletti, G. I. (1997) The challenge of problem-based learning. Kogan Page, London. 
Buffington, J. R. (1998) Self-directed teams in the introductory information systems course: Lessons learned. In International Academy for Information Management Proceedings $13^{\text {th }}$ Annual Conference, pp. 76-82.

EI-Shinnawy, M. and Vinze, A. S. (1998) Polarization and Persuasive Argumentation: A Study of Decision Making in Group Settings. Management Information Systems Quarterly, 22, (2), pp. 165-198.

Frederickon, S. (1999) Web-based Instruction: A Comparison of Ten Programs. In Proceeding of the $15^{\text {th }}$ Annual Conference in Distance Teaching and Learning, Madison, WI.

Harasim, L. (Sept. 1999) A Framework for Online Learning: The Virtual U. IEEE Computer, 32:9, pp. 44-49.

Holmes, W. N. (Sept 1999) The Myth of the Educational Computer. IEEE Computer, 32:9, pp $36-42$.

Milheim, W. D. and Harvey, D. M. (Feb 1998) Design and Development of a World Wide Web Resource Site. Educational Technology the magazine for managers of change in education, Volume 38, No. 1, pp. 53-56.

Roblyer, M. D., Edwards, J. and Havriluk, M. A. (1997) Integrating educational technology into teaching. Prentice-Hall Upper, Saddle River, NJ.

Sloan, A. (1997) Learning with the Web: Experience of using the World Wide Web in a learning environment. Computers and Education, Vol. 28, No. 4, pp. 207-212.

Tang, C., Lai, P., Tang, W., Davies, H., Frankland, S., Oldfield, K.,Walters, M., Mei Leung, N. G., Taylor, G., Tiwai, A., Yim, M. and Yuen, E. (1997) Developing a context based PBL model. Research and Development in Problem Based Learning, Vol 4, Newcastle: Australian Problem Based Learning Network, pp. 579-595.

Weible, R. (1999), Course Web site: Student preferences and good examples. International Academy for Information Management Proceedings $14^{\text {th }}$ Annual Conference, pp. 203-207.

\section{BIOGRAPHY}

Willie Yip has undertaken a number of funded learning and teaching projects in the past few years. He has the experience of running virtual teams for Hong Kong and US students for problem-based learning. Recently, he has introduced problem-based learning with technical support to his teaching in Information Systems Analysis with great success. 